Olgu Sunumu/Case Report

\title{
Apendiks mukoselinde BT kolonoskopi bulguları
}

CT colonoscopy findings of appendix mucocele

Kerim Aslan*, Mehmet Selim Nural, Hüseyin Çebi, Altan Çalmaşur, Murat Danacı

Ondokuz Mayıs Üniversitesi Tıp Fakültesi Radyodiagnostik Anabilim Dalı, Samsun

MAKALE BİGILERI ÖZET

Makale Geçmişi:

Geliş $\quad 07 / 12 / 2007$

Kabul 21/04/2008

\section{* Yazışma Adresi: \\ Kerim Aslan \\ Ondokuz Mayıs Üniversitesi \\ Tıp Fakültesi \\ Radyodiagnostik Anabilim Dalı \\ 55139 Samsun \\ E-posta : mdkerim@hotmail.com}

\section{Anahtar Kelimeler: \\ Apendiks Mukoseli \\ BT Kolonoskopi \\ Müsinöz Kistadenom}

Key Words :

Appendix Mucocele

CT colonoscopy

Mucinous Cystadenoma

\begin{abstract}
Apendiks lümeninde anormal mukus birikimi sonucu gelişen mukosel, retansiyon kisti şeklinde olabildiği gibi mukozal hiperplazi, kistadenom veya kistadenokarsinoma sekonder de gelişebilir. Bu yüzden operasyon öncesi gerek tanının konması gerekse eşlik eden başka bir patolojinin ortaya çıkarılması oldukça önemlidir. Biz bu olgu sunumunda, patolojisi musinöz kistadenom olan apendiks mukoselinin, tanısında kullanılan tüm görüntüleme yöntemleri ile birlikte BT kolonoskopi bulgularını da sunmayı amaçladık.
\end{abstract}

J. Exp. Clin. Med., 2009; 26:86-89

\begin{abstract}
Appendiceal mucocele, which results from distantion of the lumen by abnormal accumulation of mucous, can be caused by retantion cyst, mucosal hyperplasia, cystadenoma or cystadenocarcinoma. For this reason it is very important to make the diagnosis before operation and to reveal the presence of any other associated pathology. Here, we present a case of appendiceal mucocele with pathological diagnosis of mucinous cystadenoma and findings of imaging methods used in diagnosis were described, together with the findings of CT colonoscopy.

J. Exp. Clin. Med., 2009; 26:86-89
\end{abstract}

(C) 2009 OMÜ Tüm Hakları Saklıdır.

\section{Giriş}

Apendiks mukoseli oldukça nadirdir. Apendektomi yapılan hastaların sadece \%0,2 - 0,3'ünde görülmektedir (Connor ve ark., 1998). Apendiks mukoseli benign olabildiği gibi, kolonik adenokarsinom da eşlik edebilir. Bu yüzden operasyon öncesi gerek tanının konması gerekse eşlik eden patolojinin ortaya çıkarılması oldukça önemlidir. Biz bu olgu sunumunda, patolojik olarak musinöz kistadenom tanısı almış apendiks mukoseli olan bir olgunun tanısında kullanılan US bulgularını ve günümüzde yeni bir yöntem olan, literatürde daha önce sadece 2 vakanın değerlendirilmesinde kullanılmış BT kolonoskopinin bulgularını sunmayı amaçladık.

\section{Olgu Bildirimi}

Kırk-iki yaşındaki bayan hasta, vajinal akıntı, sağ orta kadranda pozisyonla ilgili silik ağrı, kramp hissi ve karında şişlik şikayetleri ile kadın doğum polikliniğine başvurdu. Hastanın öyküsünden şikayetlerinin 4 aydır devam ettiği bunlardan başka şikayetlerinin olmadığ öğrenildi. Hastanın daha önce geçirilmiş bir operasyon öyküsü yoktu. Hastanın fizik bakısında sağ alt kadranda hassasiyet dışında bulgu saptanmadı. Laboratuar incelemelerinden tam kan sayımı ve kan biyokimya değerleri normal sınırlarda bulundu. Dış merkezde yapılan pelvik USG'de, batın sağ alt kadranında kistik tübüler yapı tespit edilen hasta, bölümümüze lezyonun orijini ortaya çıkarmak ve gastrointestinal bir patolojiyi ekarte etmek amaciyla sa- 
nal BT kolonoskopi tetkiki yapılmak üzere gönderildi. Hastaya yapılan rutin barsak temizliğinin ardından kolonik distansiyonu sağlamak amaciyla manuel serbest hava uygulanmıştır. Supin ve pron pozisyonda, kranio-kaudal yönde, tüm kolon segmentlerini ve rektumu içerecek şekilde 16 kesiti BT cıhazı ile (Aquillon, Toshiba) abdomen ve pelvik BT incelemesi yapıldı. Çekim parametreleri 120 $\mathrm{kV}, 75 \mathrm{mAs}, 1 \mathrm{~mm}$ kolimasyon, $1 \mathrm{~mm}$ rekonstruksiyon intervali idi. Aksiyel çekim yapıldıktan sonra kaynak görüntüler Vitrea iş istasyonuna transfer edilerek, ilk olarak aksiyel plandaki supin ve pron pozisyonlardaki görüntüler değerlendirildi. Gölgeli yüzeysel gösterim (SSD = Shaded Surface Display), Hacimsel gösterim (VRT = Volumerendering technique) algoritmalarının yer aldığı bilgisayar programları ile sanal kolonografi ve sanal kolonoskopi yapıldı. Daha sonra iki pozisyonda koronal ve sagittal çoklu açıdan görüntüler (MPR=multiplanar rekonstrüksiyon) değerlendirildi. Aksiyel plandaki 2 boyutlu görüntülerde; apendiksin beklenen lokalizasyonunda, çekum tabanına indentasyon yapan kistik tubuler bir yapı izlendi. Sanal kolonoskopide, çekumda lümen içerisine doğru protruzyon gösteren polipoid, düzgün sınırlı, yaklaş1k $21 \mathrm{~mm}$ çapında oluşum dikkati çekti (Şekil 1). MPR, kavisli görüntü $(\mathrm{CPR}=$ curved planar reformation) ve 3 boyutlu görüntüler birlikte değerlendirildiğinde; bu oluşumun apendiksin beklenen lokalizasyonunda, çekum tabanına indentasyon yapan inferior ve mediale doğru uzanım gösteren, en geniş çap1 $3 \mathrm{~cm}$ 'ye varan, 8-9 cm uzunlukta, tübüler kör sonlanan, içi sıvı dolu tübüler bir yapı olduğu görüldü (Şekil 2). Hastaya tarafimızdan yapılan USG'de, çekum tabanında, çekuma bası etkisi oluşturan, pelvis içerisine doğru uzanan, kıvrıml1, tübüler, posterior güçlenme veren, anekoik kistik yap1 görüldü (Şekil 3). Bu bulgularla radyolojik olarak apendiks mukosel tanısı kondu. BT kolonoskopi de lümen içi ve ekstrakolonik ek bir patoloji saptanmadi. Hasta opere edildi. Patoloji sonucu ise musinöz kistadenom olarak geldi.

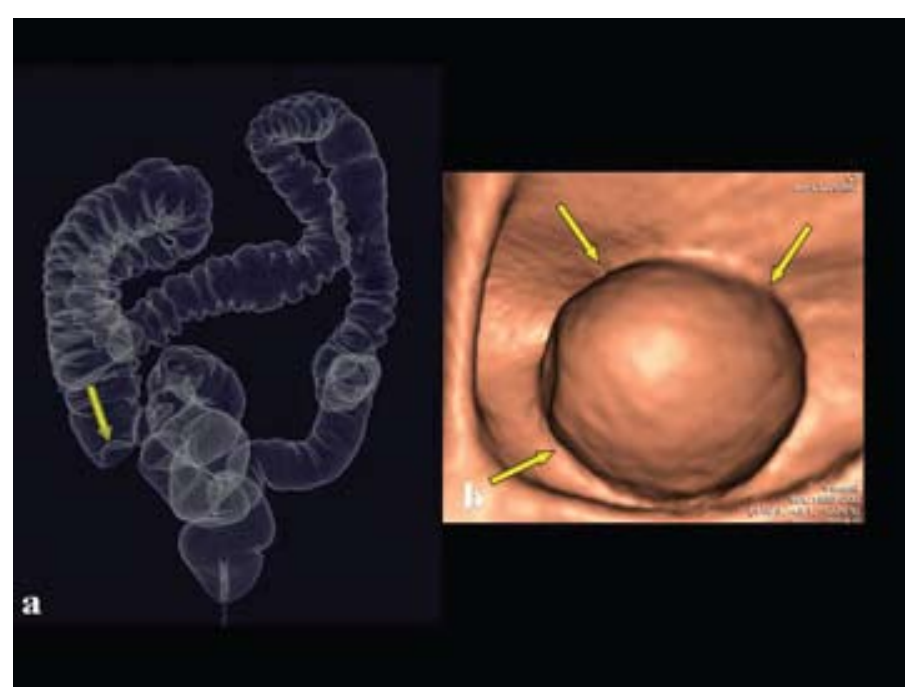

Şekil 1. Sanal kolonografide (a) ve sanal kolonoskopide (b) çekumda lümen içerisine doğru protrüzyon gösteren polipoid, düzgün sınırlı lezyon (oklar) dikkati çekti.

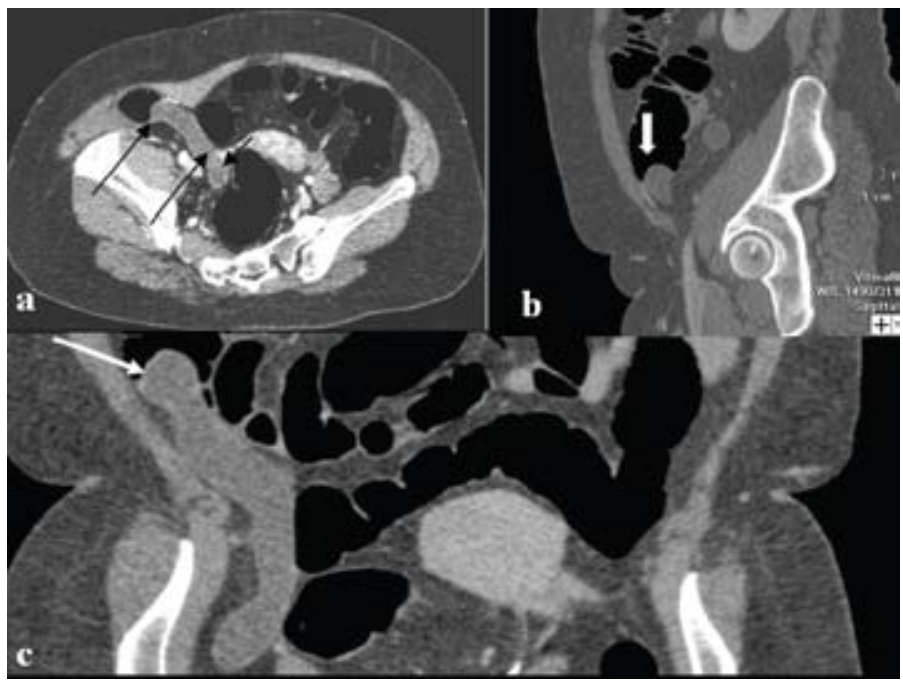

Şekil 2. Çekum tabanına indentasyon yapan inferior ve mediale doğru uzanım gösteren sıvı dansitesinde 9x3 cm boyutlarında tübüler kör sonlanan apendiks mukoseline ait görünüm (oklar), BT kolonoskopide kavisli aksiyel (a) ve koronal (c), sagittal çoklu açıdan görüntülerde (b) net olarak izlenmektedir. Ayrıca sağ overde kist (a da kısa siyah ok) dikkati çekmektedir.

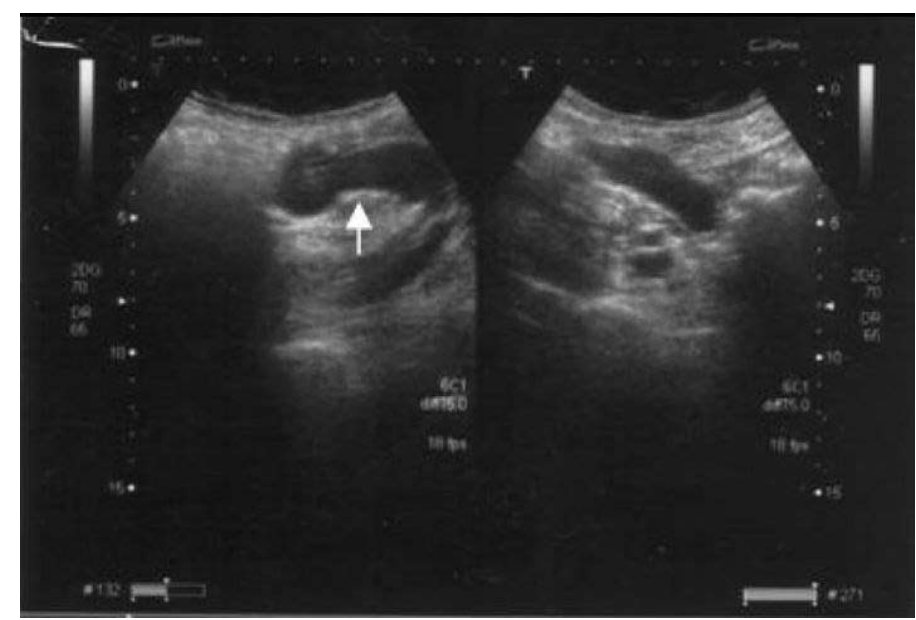

Şekil 3. Abdominal USG de çekum tabanında, çekuma bası etkisi oluşturan pelvis içerisine doğru uzanan, kıvrımlı tübüler, anekoik posterior güçlenme veren mukosel (ok) görüldü.

\section{Tartıșma}

Apendiks mukoseli, lümeninin anormal mukus birikimi sonucu gelişen bir distansiyonu olup, 4 farklı nedenle ortaya çıkabilmektedir. Bunlar; retansiyon kisti, mukozal hiperplazi, kistadenom ve kistadenokarsinomdur (Landen ve ark., 1992; Zissin ve ark., 1999). Nadir bir hastalık olan apendiks mukoseli, en sık 50 yaşın üzerinde görülür ve kadınlarda erkeklerden dört kat daha sıktır (Aho ve ark., 1973).

Vakaların \% 23-50'si asemptomatik seyretmektedir. Semptomatik vakalardaki tipik bulgular ise sağ alt kadran ağrıs1, gastrointestinal kanama ve ele gelen abdominal kitle şeklinde olmakla beraber spesifik değildir (Aho ve ark., 1973; Landen ve ark., 1992; Zissin ve ark., 1999). Olgumuzda klinik bulgular sağ orta kadranda pozisyonla ilgili silik ağrı, kramp hissi ve karında şişlik şikayetleri olup non-spesifikdi. Bu nedenle klinik bulgular tanı koymada yetersiz olup görüntüleme yöntemleri tanıyı koyma- 
da ön plana çıkmaktadır.

Apendiks mukoselinin tipik radyolojik bulgusu, apendiks bölgesinde kistik kitle varlığıdır. Direkt grafide; sağ alt kadranda kitle şeklinde bulgu verebilir. Kitlenin duvarında mural kalsifikasyon görülmesi apendiks mukoseli için spesifisitesi yüksek bir bulgudur. Ancak bu bulgu \%50'den daha az sıklıkta görülür (Pickhardt ve ark., 2003). Baryumlu kolon incelenmesinde; apendiks görüntülenemeyebilir, çekum yada terminal ileumda mukoza ülserasyonu görülmeksizin submukozal kitle ya da ekstrinsik basıyı düşündüren görünüm izlenebilir (Dachman ve ark., 1985; Bahia ve Wilson, 1989).

Tanıda en önemli iki yöntem US ve BT'dir. Apendiks mukoseli USG'de, mukoid materyallere bağlı internal ekolar içeren, anekoik-hipoekoik kistik kitleler şeklinde görülür. Musin varlığının ses dalgasının gücünü azaltması nedeniyle posterior akustik güçlenmeler genellikle beklenmez. Kist duvarı, klasik kist görüntüsünün aksine daha az belirgindir (Sasaki ve ark., 2003). Eğer mukosel büyükse $(>20 \mathrm{~cm})$ soğan kabuğu işareti (kitle içindeki yoğun mukoid materyalin dalgalı paterni) genellikle görülür (Francica ve ark., 2006). Olgumuzda US'de, ince düzgün duvarlı anekoik kistik lezyon, posterior güçlenme vermekte olup internal eko içermemekteydi. Mukoselin BT'deki tipik bulguları ise, apendiks lokalizasyonunda, çevresinde inflamatuar reaksiyon olmaksızın, çekal duvarda ekstrinsik basiya sebep olan, internal septasyonlar ve bazen mural kalsifikasyonla birlikte bulunan, kistik, iyi kapsüllü, yuvarlak yada tübüler lezyon şeklindedir.

Yoğunluk değerleri, sıvıdan yumuşak doku dansitesine kadar değişebilmektedir. Duvarda kontrast madde tutulumu gösteren mural nodüller mukoselin malign olabileceğini düşündürür (Horgan ve ark., 1984; Dachman ve ark., 1985; Madwed ve ark., 1992; Kim ve ark., 1998;
Krebs ve ark., 1998). Olgumuzda BT'de eşlik eden kalsifik ya da non-kalsifik herhangi bir nodüler lezyon, kontrastlanma ve internal septasyon yoktu. Bu yüzden malign bir patoloji düşünülmedi. Bu bulgulara ek olarak kist komşuluğunda perforasyona sekonder asit izlenebilir. Asitin yaygın olması, septasyonlar içermesi, direk invazyon yapmadan abdominal visseral organlara eksternal bası yapan düşük dansiteli yumuşak doku kitlelerinin izlenmesi, ender görülen fakat önemli bir komplikasyon olan psödomiksoma peritonei gelişimini akla getirmelidir (Zissin ve ark., 1999). Mukoselle birlikte görülen diğer komplikasyonlar ise; rüptür, torsiyon, olası bir obstruksiyon ile birlikte barsağa herniasyon ve invajinasyondur (Sasaki ve ark., 2003).

Mukoselin ayırıcı tanısında sağ over kisti, sağ hidrosalfinks, mezenter kisti, duplikasyon kisti, inflamatuar barsak hastalıkları, komplike divertikülit ve kronik hematom sayılabilir (Skaane ve ark., 1988; Zissin ve ark., 1999). Ayrıca apendiks mukoseline \%21,4 oranında kolonik adenokarsinom eşlik edebilir. Olgumuzda BT kolonoskopik inceleme ile kolonda başka bir patoloji olmadığ gösterildi. Böylece hastaya kolonda başka bir patoloji varlığ 1 için ek bir invaziv veya non-invaziv bir işleme gerek kalmamıştır.

\section{Sonuç}

USG non-invaziv bir yöntem olması ve anlamlı bulgular içermesi nedeniyle birinci basamak tanı yöntemi olarak düşünülür. BT ve BT kolonoskopi, lezyon ve lezyonun komşuluğundaki organlar arasındaki anatomik ilişkiyi daha iyi göstermektedir. Ayrıca apendiks mukoselinin nedenini ortaya koymada, komplikasyonlarını göstermede, ayırıcı tanıda ve eşlik eden kolonik adenokarsinomu saptamada daha etkin bir role sahiptir.

\section{KAYNAKLAR}

Aho AJ., Heinonen R., Lauren P., 1973. Benign and malignant mucocele of the appendix Acta Chir. Scand. 139, $392-400$.

Bahia JO, Wilson MH., 1989. Mucocele of the appendix presenting as an adnexal mass. J. Clin. Ultrasound 17, $62-66$.

Connor SJ, Hanna GB, Frizelle FA., 1998. Appendiceal tumors: retrospective clinicopathologic analysis of appendiceal tumors from 7, 970 appendectomies. Dis Colon Rectum. 41, 75-80.

Dachman AH, Lichtenstein JE. Friedman AC., 1985. Mucocele of appendix and pseudomyxoma peritonei. AJR. 144, $923-929$.

Francica G, Lapiccirella G, Giardiello C, Scarano F, Angelone G, De Marino F, Molese V., 2006. Giant mucocele of the appendix. Clinical and imaging findings in 3 cases. J. Ultrasound Med. 25,643-648.

Horgan JG, Chow PP, Richter JO, Rosenfield AT, Taylor KJ., 1984. CT and sonography in the recognition of mucocele of the appendix. AJR. 143, 959-961.

Kim SH, Lim HK, Lee WJ, Lim JH, Byun JY., 1998. Mucocele of the appendix: ultrasonographic and CT findings. Abdominal Imaging 23, 292-296.

Krebs TL, Daly BD, Wong-You-Cheong JJ, Grumbach K., 1998. General case of the day. Mucinous cystadenocarcinoma of the appendix. Radiographics 18, 1049-50.

Landen S, Bertrand C, Maddern GJ, Herman D, Pourbaix A, de Neve A, Schmitz A, 1992. Appendiceal mucoceles and pseudomyxoma peritonei. Surg. Gynecol. Obstet. 175, 401-404.

Madwed D, Mindelzun R. Jeffrey RB., 1992. Mucocele of the appendix: imaging findings AJR. 159, 69-72.

Pickhardt PJ, Levy AD, Rohrmann CA Jr, Kende AI., 2003. Primary neoplasms of the appendix: radiologic spectrum of disease with 
pathologic correlation. Radiographics 23, 645-662.

Sasaki K, Ishida H, Komatsuda T, Suzuki T, Konno K, Ohtaka M, Sato M, Ishida J, Sakai T, Watanabe S., 2003. Appendiceal mucocele: sonographic findings. Abdom. Imaging. 28, 15-18.

Skaane P, Ruud TE, Haffner J., 1988. Ultrasonographic features of mucocele of the appendix. J. Clin. Ultrasound 16, 584.

Takahashi S, Furukawa T, Ueda J., 1998. Case report: Mucocele of the tip of the appendix. Clin Radio. 53, $149-150$.

Wolff M, Ahmed N., 1976. Epithelial neoplasm of the vermiform appendix (exclusive of carcinoid). Cancer 37, $2511-2522$.

Zissin R, Gayer G, Kots E, Apter S, Peri M, Shapiro-Feinberg M., 1999. Imaging of mucocoele of the appendix with emphasis on the CT findings: a report of 10 cases. Clin. Radiol. 54, 826-832. 